\title{
EDITORIAL
}

\section{Search and Rescue Is Search and Rescue-Or, the Basics Still Apply}

The discussion in this issue of Wilderness \& Environmental Medicine regarding the survival of Caenorhabditis elegans subsequent to the space shuttle Columbia disaster ${ }^{1}$ uses what, on the surface, could appear to be a trivial finding and transforms it into a springboard to point out the implications for the survival of the crew in the event of a spacecraft mishap. The authors do this through a methodical dissection of the core challenges that must be dealt with in order to enhance the likelihood of crew survival subsequent to any aerospace mishap. Their distillation of the process consists of the discrete critical elements of 1) surviving breakup and exposure to the atmosphere, 2) surviving impact with the Earth's surface, and 3) surviving until recovery provides a useful framework upon which to address the challenges to survival. In fact, these general categories are quite similar to the ones used in 1987 at NASA in the formulation and development of the escape system that is in use on the space shuttle today. While not new, this effective systems-based approach to addressing the challenges of crew survival is all too often ignored once concentration turns to the design, fabrication, and implementation of component mitigation strategies (ie, parachutes, rafts, locator beacons).

The authors' reduction to first principles and avoidance of jumping to conclusions are important, as demonstrated by their point that the lack of egress does not necessarily mean the lack of survival. Both the Challenger and Columbia mishaps were initially believed by most, and still erroneously thought by many, to have resulted in the almost immediate deaths of the crew, which was ultimately and conclusively shown not to have been the case. ${ }^{2}$ What's more, these or similar events can be survivable with appropriate planning. This emphasizes the important point that accident investigators must always keep in the forefront of their minds, namely that the evidence must lead you to your conclusions and not the other way around. When this is not practiced, the risk of confirmation bias that can lead to erroneous conclusions and flawed mitigation strategies is particularly high.
Another easily overlooked but extremely important point made by the authors is the observation that search teams should consult those knowledgeable in the design of the spacecraft. The expertise of such individuals can prove invaluable, because they can assist in focusing the search more precisely on the area where debris may have fallen. This is especially important in the case of a mishap involving a spacecraft breakup during entry, since the debris can be scattered over hundreds of square miles, as was the case with Columbia. Although other aviation mishaps are not likely to involve quite as large an area, the increased efficiency of a search that has the benefit of those who are not only familiar with the design of the craft in question but who also understand the crew's contingency survival procedures and capabilities can be a substantial asset in reducing the time until the crew is located, thus enhancing the probability of survival. Another benefit to having knowledgeable individuals present during the search and recovery is that valuable evidence, which may be critical to understanding the factors that can lead to an increased chance of crew survival in the future, is less likely to be overlooked.

Overall, the ability of the authors to extrapolate from the survival of a primitive organism such as $C$ elegans to the general principles underlying a complete searchand-rescue effort demonstrates that the basic principles of search-and-rescue operations are applicable across a multitude of scenarios.

\section{References}

1. Szewczyk NJ, McLamb W, Conley CA. Surviving atmospheric spacecraft breakup. Wilderness Environ Med. 2005; 16:27-32.

2. Bagian JP, White DJ. Crew survivability report. In: Board CAI, ed. Columbia Accident Investigation Board Report. Washington, DC: Columbia Accident Investigation Board; 2003:349-366.

James P. Bagian, MD Northville, MI, USA 